\title{
EVALUASI KINERJA TRAYEK AKDP DARI TERMINAL BARUGA KE BERBAGAI JURUSAN DI WILAYAH PROVINSI SULAWESI TENGGARA
}

\author{
Sumariyani $^{1)}$, Irwan Lakawa ${ }^{2}$, La Ode Muhammad Magribi ${ }^{3)}$ \\ ${ }^{1}$ Program Studi Teknik Sipil, Fakultas Teknik, Universitas Sulawesi Tenggara \\ e-mail : anhey.zx@gmail.com \\ ${ }^{2}$ Program Studi Teknik Sipil, Fakultas Teknik, Universitas Sulawesi Tenggara \\ e-mail : ironelakawa@gmail.com \\ ${ }^{3}$ Program Studi Teknik Sipil, Fakultas Teknik, Universitas Sulawesi Tenggara \\ e-mail : obi_magribi@yahoo.com
}

\begin{abstract}
ABSTRAK
Penelitian ini bertujuan untuk mengevaluasi kinerja angkutan kota dalam provinsi saat ini dan menganalisis kebutuhan moda angkutan kota dalam provinsi. Teknik analisis data menggunakan persamaan matematis dengan bantuan Software Microsoft Excel. Titik pengamatan berada di Terminal Baruga Kota Kendari

Hasil penelitian menunjukkan bahwa waktu perjalanan pergi pulang dari 8 trayek studi hanya 6 trayek yang memenuhi standar World Bank, yaitu trayek Torobulu, Andoolo, Lainea, Tinanggea, Palangga dan Motaha. Untuk frekuensi kendaraan hanya 4 trayek yang memenuhi standar World Bank yaitu trayek Bambaea, Lainea, Tinanggea dan Palangga. Dari aspek faktor muat yang tertinggi terdapat pada trayek Torobulu, Lainea dan Palangga, sedangkan yang terendah terdapat pada trayek Boepinang. Dari aspek selisih waktu tidak satupun yang memenuhi nilai standar World Bank. Dari aspek waktu siklus hanya 1 trayek yang tidak memenuhi standar yaitu trayek Boepinang. Kebutuhan moda Angkutan Kota Dalam Provinsi di Terminal Baruga belum memenuhi standar karena Jumlah kendaraan yang beroperasi jauh lebih sedikit dari jumlah kendaraan yang ditetapkan oleh Dinas Perhubungan Provinsi Sulawesi Tenggara.
\end{abstract}

Kata Kunci : Terminal, Kinerja, Kebutuhan Moda.

\begin{abstract}
This study aims to evaluate the performance of urban transport in the current province and analyze the needs of urban transport modes in the province. The data analyze technique uses mathematical equations with the help of microsoft excel software. The observation point is in the city Baruga Terminal Kendari.

The results showed that the trip to go home from 8 study routes was only 6 routes that met World Bank standards, namely Trobulu, Andoolo, Lainea, Tinanggea, Palangga and Motaha routes. For vehicle frequencies only 4 routes meet World Bank standards, namely the routes of Bambaea, Lainea, Tinanggea and Palangga. The highest aspects of load factor are found on the Torobulu, Lainea and Palangga routes, while the lowest is on the Boepinang route. None of the time headway aspects met the values of the World Bank standard. From the aspect of cycle time only 1 route does not meet the standard, namely the Boepinang route. The need for city transportation in the province in Terminal Baruga does not meet the standards because the number of vehicles set by the transportation service of Southeast Sulawesi Province.
\end{abstract}

Keywords : Terminal, Performance, Needs Mode. 


\section{PENDAHULUAN}

Terminal Baruga merupakan Terminal tipe B yang berdiri kokoh di atas lahan seluas 4,45 hektar yang pembangunannya diresmikan pada 6 oktober 2017 berfungsi melayani kendaraan umum untuk angkutan kota dalam provinsi (AKDP), DAMRI serta Bus TRANSLULO. Terkait hal tersebut dalam melakukan aktivitasnya angkutan antar kota masih memiliki kualitas pelayanan yang kurang memadai, salah satu penyebabnya adalah kurangnya kendaraan angkutan antar kota yang beroperasi di Terminal Baruga, dalam arti tidak ada keseimbangan antar besar kebutuhan pergerakan (demand), dengan penyediaan (supply). Kurangnya kendaraan yang beroperasi di dalam Terminal Baruga ini disebabkan karena sebagian mobil angkutan penumpang masih beroperasi di Pasar Rakyat Baruga yang letaknya kurang lebih $500 \mathrm{M}$ dari Terminal Baruga.

Adanya sistim telfon penumpang juga menjadi salah satu penyebab kurangnya jumlah penumpang yag ada di Terminal Baruga, para penumpang tidak perlu repot-repot menunggu mobil angkutan tujuan mereka di terminal, mereka cukup menelfon mobil angkutan penumpang tujuan mereka tersebut dan menunggunya menjemput di kediamannya. Hal ini menyebabkan kurangnya mobil penumpang umum AKDP yang beroperasi di dalam Terminal Baruga. Mobil penumpang umum yang beroperasi di Terminal Baruga hanya 8 trayek, trayek tersebut yaitu trayek Bambaea, trayek Torobulu, trayek Andoolo, trayek Boepinang, trayek Lainea, Trayek Tinanggea, trayek Palangga dan trayek Motaha.

Untuk memperbaiki keadaan ini, maka perlu segera dilakukan tindakan-tindakan konkrit dalam meningkatkan pelayanan angkutan antar kota di Terminal Baruga Kota Kendari baik yang menyangkut kapasitas pelayanan, jaringannya serta penggunaan modanya. Berdasarkan uraian permasalahan tersebut maka peneliti tertarik untuk mengevaluasi kinerja trayek Angkutan Kota Dalam Provinsi dari Terminal Baruga ke berbagai jurusan di wilayah Sulawesi Tenggara.

\section{TINJAUAN PUSTAKA}

\section{A. Terminal}

Terminal merupakan unit fasilitas untuk pelayanan umum, dalam hal ini pergerakan manusia dan barang dari suatu tempat ke tempat lain. Menurut World Bank (1987) dalam Sibagariang (2014) terminal adalah titik tempat penumpang dan barang memasuki dan meninggalkan suatu sistem transportasi. Terminal ini bukan saja merupakan komponen fungsional utama dari sistem transportasi tetapi juga merupakan prasarana yang memerlukan biaya yang besar dan titik tempat kongesti (kemacetan) mungkin terjadi.

\section{B. Angkutan Kota Dalam Provinsi (AKDP)}

Angkutan kota dalam provinsi adalah angkutan dari satu kota ke kota lain yang memalui antar daerah kabupaten atau kota dalam satu daerah provinsi dengan menggunakan mobil bus umum yang terikat dalam trayek. Menurut Keputusan Menteri Perhubungan Nomor 35 Tahun 2003 tentang Penyelenggaraan Angkutan Orang di Jalan Dengan Kendaraan Umum pada Pasal 1 disebutkan bahwa angkutan adalah pemindahan orang atau barang dari satu tempat ke tempat lain dengan menggunakan kendaraan. Kendaraan umum adalah setiap kendaraan bermotor yang disediakan untuk dipergunakan oleh umum dengan dipungut bayaran baik langsung maupun tidak langsung. Adapun Angkutan Antar Kota Dalam Propinsi (AKDP) adalah angkutan dari satu kota ke kota lain yang melalui antar daerah kabupaten atau kota dalam satu daerah propinsi dengan menggunakan mobil bus umum yang terikat dalam trayek. Pengoperasian AKDP hingga saat ini belum memiliki SPM (Standar Pelayanan Minimum). Adapun standar pelayanan angkutan perkotaan yang dikeluarkan oleh kementerian perhubungan tidak lengkap. Sementara itu World Bank telah mengeluarkan standar pelayanan angkutan umum perkotaan yang bisa diacu untuk 
standar pelayanan angkutan umum lainnya sebelum munculnya standar pelayanan angkutan umum menurut jenisnya. Adapun kinerja angkutan umum dengan trayek tetap berdasarkan World Bank, terlihat pada tabel 1.

Tabel 1 : Standar Angkutan Umum Menurut World Bank.

\begin{tabular}{|c|l|l|c|}
\hline No & \multicolumn{1}{|c|}{ Parameter } & \multicolumn{1}{|c|}{ Satuan } & Standar \\
\hline 1 & Headway & Menit & Rata-rata jarak perjalanan (Km/hari) \\
\hline 2 & Jarak Tempuh & $\begin{array}{l}\text { \% rasio jumlah penumpang yang ada di } \\
\text { dalam bus dengan kapasitas tempat duduk } \\
\text { yang ada }\end{array}$ & $230-260$ \\
\hline 3 & Faktor Pengisian (Load Factor & 70 \\
\hline 4 & Waktu Tempuh & Jam & $\begin{array}{c}\text { Rata-rata 1-1,5 } \\
\text { Maksimum 1,5-2 }\end{array}$ \\
\hline
\end{tabular}

Sumber: Risdiyanto, dkk (2013).

\section{Kinerja Angkutan Umum}

World Bank dan Hubungan Darat mengeluarkan standart pelayanan untuk angkutan perkotaan yang dibagi dalam dua hal yaitu indikator kinerja operasi dan indikator kualitas pelayanan. Adapun nilai standar kinerja angkutan umm dapat dilihat pada tabel 2.

Tabel 2 : Nilai standar Kinerja Angkutan Umum.

\begin{tabular}{|c|c|c|c|}
\hline No & Jenis Parameter & Satuan & $\begin{array}{c}\text { Nilai } \\
\text { Standar }\end{array}$ \\
\hline \multirow[t]{9}{*}{1} & \multicolumn{3}{|c|}{ A. Volume Penumpang (Passenger Volume) Menurut World Bank } \\
\hline & 1) Single Deck (Kapasitas 80) & Orang & $1000-1200$ \\
\hline & 2) Single Deck (Kapasitas 100) & Orang & $1200-1500$ \\
\hline & \multicolumn{3}{|c|}{ B. Volume Penumpang (Passenger Volume) Menurut Hubdat } \\
\hline & 1) Bus Lantai Ganda & Orang & 1500 \\
\hline & 2) Bus Lantai Tunggal & Orang & 1000 \\
\hline & 3) Bus Patas Lantai Tunggal & Orang & 625 \\
\hline & 4) Bus Kecil & Orang & 400 \\
\hline & 5) MPU & Orang & 250 \\
\hline \multirow[t]{3}{*}{2} & \multicolumn{3}{|l|}{ Frekuensi Minimum } \\
\hline & A. Rata-rata & Kend/jam & $3-6$ \\
\hline & B. Maksimum & Kend/jam & $1,5-2$ \\
\hline \multirow[t]{3}{*}{3} & \multicolumn{3}{|l|}{ Waktu Tunggu (Waiting Time) } \\
\hline & A. Rata-rata & Menit & $5-10$ \\
\hline & B. Maksimum & Menit & $10-20$ \\
\hline \multirow[t]{3}{*}{4} & Waktu Tempuh Perjalanan (Journey Time) & & \\
\hline & A. Rata-rata & Jam & $1-1,5$ \\
\hline & B. Maksimum & Jam & $2-3$ \\
\hline 5 & Faktor Muat (Load Factor) & $\%$ & $<100$ \\
\hline 6 & Jumlah Trip dan jarak Tempuh Kendaraan & $\mathrm{Km}$ & $230-260$ \\
\hline 7 & Waktu Siklus & Jam & $5-10$ \\
\hline 8 & Jumlah Kendaraan & $\%$ & $80-90$ \\
\hline
\end{tabular}

Sumber: Keputusan Direktorat Jendral Perhubungan Darat (2002). 


\section{Parameter Kinerja Angkutan Umum \\ 1. Waktu Perjalanan}

Waktu perjalanan adalah waktu yang dibutuhkan oleh kendaraan untuk melewati ruas jalan yang diamati, termaksud waktu berhenti untuk menaikkan dan menurunkan penumpang. Waktu perjalanan tergantung pada kecepatan, panjang rute dan kondisi lalu lintas. Waktu perjalanan dari tiap trayek relatif sangat berfariasi, di satu sisi ada yang mempunyai waktu relative singkat, dan di sisi lain ada yang mempunyai waktu relative lama. Adapun lama perjalanan ke dan dari tempat tujuan setiap hari rekomendasi World Bank rata-rata 1 - 1,5 jam, maksimum 2 - 3 jam (Yafiz 2002).

\section{Frekuensi Kendaraan}

Frekuensi kendaraan diperoleh dari mengamati jumlah kendaraan per jam atau per hari di terminal untuk tiap trayeknya. Dari jumlah kendaraan per jam atau per hari tersebut kemudian dicari waktu sibuk dan tidak sibuk tiap-tiap trayek.

\section{Faktor Muat (Load Factor)}

Analisis load factor dimaksudkan untuk mengukur kapasitas penumpang setiap kali perjalanan, sehingga dari data load factor nantinya dapat diketahui apakah kendaraan dari setiap trayek mampu mengangkut penumpang dalam kapasitas maksimal.

$$
\text { Load Factor }=\frac{\text { Jumlah penumpang }}{\text { Kapasitas kendaraan }} \times 100 \%
$$

\section{Jumlah Trip Dan Jarak Tempuh Per Kendaraan Per Hari}

Karena adanya perbedaan jarak tempuh antar trayek, maka jumlah trip per kendaraan per hari tidak dapat dijadikan dasar untuk membandingkan kinerja angkutan penumpang yang lebih tepat adalah membandingkan jarak tempuh per kendaraan per hari. Jumlah trip itu sendiri merupakan banyaknya kendaraan melakukan perjalanan pergi pulang tujuan.

\section{Jumlah Penumpang Per Kendaraan Per Hari}

Jumlah penumpang per kendaraan di peroleh dari jumlah penumpang yang pergi atau berada dalam suatu kendaraan angkutan penumpang setiap kendaraan dalam setiap trayek.

\section{Selisih waktu (Headway)}

Selisih waktu (headway) merupakan interval waktu dimana saat bagian depan suatu kendaraan melalui satu titik sampai bagian depan kendaraan berikut melalui titik yang sama (Morlok 1995, dalam Yohanes T. Safe dkk 2015). Headway dapat ditentukan menggunakan rumus:

$$
H=\frac{60}{Q / J a m}
$$

Keterangan:

$$
\begin{aligned}
& \mathrm{H} \quad=\text { Selisih waktu/headway (menit). } \\
& \mathrm{Q} / \mathrm{Jam} \text { = Jumlah kendaraan dalam satu jam. }
\end{aligned}
$$

\section{Waktu Siklus}

Waktu siklus merupakan waktu yang diperlukan kendaraan angkutan penumpang umum untuk melayani rute dalam satu kali trip (pergi-pulang) mulai dari asal, menuju ke tujuan lalu kembali lagi ke asal. Dinyatakan dengan persamaan:

$$
C T A B A=(T A B+T B A)+(\sigma A B+\sigma B A)+(\mathrm{TTA}+\mathrm{TTB})
$$


Keterangan:

CTABA $=$ Waktu siklus dari A ke $\mathrm{B}$ lalu kembali lagi ke A.

$\mathrm{TAB}=$ Waktu perjalanan rata-rata dari A ke $\mathrm{B}$.

TBA $\quad=$ Waktu perjalanan rata-rata dari $\mathrm{B}$ ke $\mathrm{A}$.

$\sigma \mathrm{AB}=$ Deviasi waktu perjalanan dari A ke B (ditetapkan 5\%).

$\sigma \mathrm{BA} \quad=$ Deviasi waktu perjalanan dari B ke A (ditetapkan 5\%).

TTA $\quad=$ Waktu henti kendaraan di A (ditetapkan 10\%).

TTB = Waktu henti kendaraan di B (ditetapkan 10\%).

\section{Jumlah Kendaraan Yang Diperlukan}

Kebutuhan angkutan penumpang merupakan penentuan jumlah armada angkutan penumpang umum, untuk menilai tingkat pelayanan yang cukup memadai. Jumlah kebutuhan angkutan penumpang dapat diperoleh dengan rumus:

$$
\begin{array}{ll}
K=\frac{C T A B}{H} \times 10 & \ldots \ldots \ldots \ldots \ldots \ldots \ldots \ldots \ldots \ldots \ldots \ldots \ldots \ldots \ldots \ldots \\
\text { Keterangan: } & \\
\mathrm{K} & =\text { Jumlah kendaraan per siklus. } \\
\text { CTAB } & =\text { Waktu siklus. } \\
\mathrm{H} & =\text { Headway (selisih waktu). }
\end{array}
$$

\section{METODE PENELITIAN}

\section{A. Lokasi Penelitian}

Lokasi penelitian ialah di Terminal Baruga Kota Kendari, letaknya di simpang tiga Institut Agama Islam Negeri (IAIN).

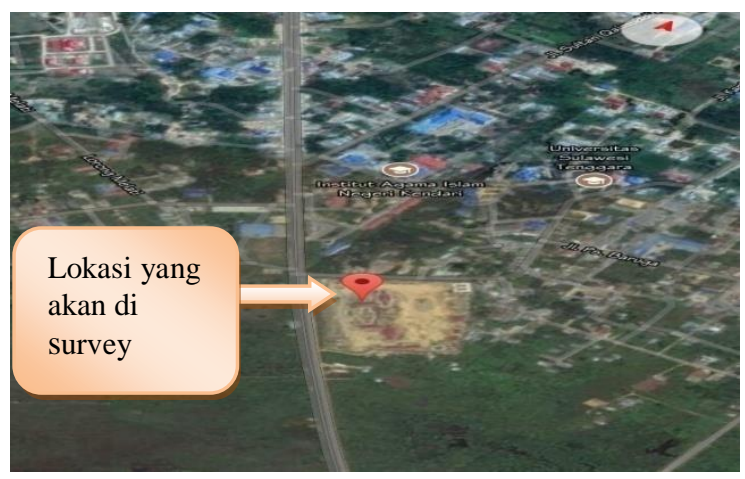

Gambar 3.1 Peta Lokasi Penelitian Sumber Google Maps

\section{B. Variabel Penelitian}

Variabel yang menjadi parameter penelitian adalah kinerja trayek dan pelayanan angkutan meliputi waktu perjalanan, frekuensi kendaraan, faktor muat, jarak tempuh per kendaraan per hari, jumlah penumpang per kendaraan per hari, waktu antara (headway), waktu siklus, jumlah kendaraan. Kebutuhan moda angkutan meliputi jumlah trayek dan jumlah armada. Variabel penelitian dapat dilihat pada tabel 1 
Tabel 1 : Variabel Penelitian.

\begin{tabular}{|c|c|c|c|c|c|}
\hline No & $\begin{array}{c}\text { Tujuan } \\
\text { penelitian }\end{array}$ & $\begin{array}{l}\text { Bentuk } \\
\text { Analisis }\end{array}$ & Variabel & Indikator & $\begin{array}{l}\text { Jenis } \\
\text { Data }\end{array}$ \\
\hline 1. & $\begin{array}{l}\text { Mengevaluasi } \\
\text { kinerja trayek } \\
\text { angkutan }\end{array}$ & Deskriptif & $\begin{array}{l}\text { Kinerja } \\
\text { pelayanan } \\
\text { angkutan }\end{array}$ & $\begin{array}{l}\text { a) Waktu perjalanan. } \\
\text { b) Frekuensi kendaraan. } \\
\text { c) Faktor muat. } \\
\text { d) Jarak tempuh per kendaraan per } \\
\text { hari. } \\
\text { e) Jumlah penumpang } \\
\text { per kendaraan per hari. } \\
\text { f) Waktu antara (headway). } \\
\text { g) Waktu siklus. }\end{array}$ & primer \\
\hline 2 & $\begin{array}{l}\text { Menganalisis } \\
\text { kebutuhan moda } \\
\text { angkutan }\end{array}$ & Deskriptif & $\begin{array}{l}\text { Mobil } \\
\text { penumpang } \\
\text { umum }\end{array}$ & $\begin{array}{l}\text { a) Kapasitas kendaraan. } \\
\text { b) Jumlah kendaraan. } \\
\text { c) Jumlah armada. }\end{array}$ & Sekunder \\
\hline
\end{tabular}

\section{HASIL DAN PEMBAHASAN}

\section{A. Kinerja Operasional AKDP di Terminal Baruga Kondisi Saat Ini.}

\section{Jaringan Trayek}

Data yang diperoleh dari Dinas Perhubungan dapat dilihat jumlah armada menurut izin, dan rute trayek. Data jumlah kendaraan dapat dipakai sebagai pembanding dengan jumlah kendaraan beroperasi pada saat survei. Sedangkan rute trayek dapat dipakai untuk mengetahui penyimpangan trayek yang dilakukan. Adapun data jumlah kendaraan menurut izin dapat dilihat pada gambar 1.

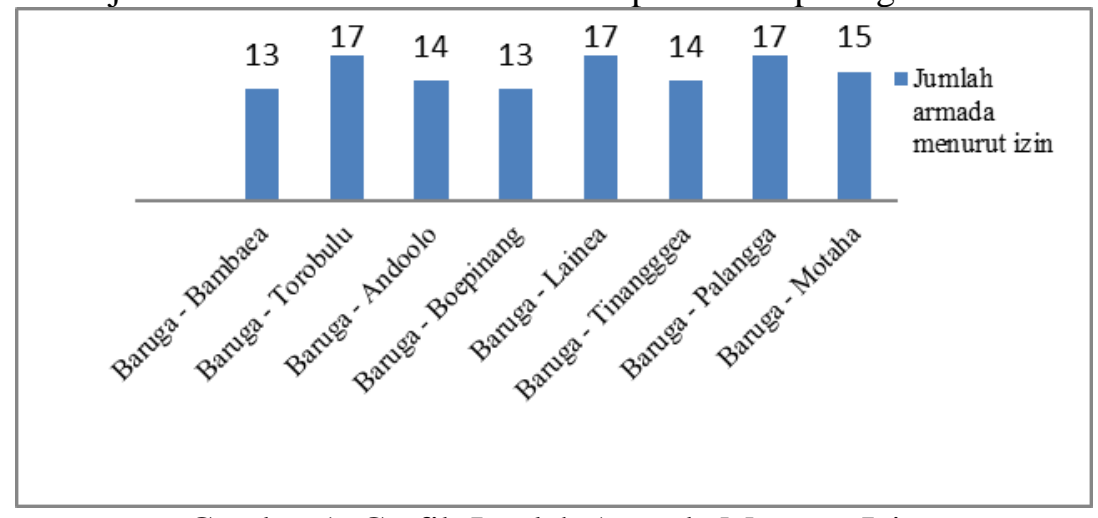

Gambar 1: Grafik Jumlah Armada Menurut Izin

Sumber : Dinas Perhubungan Provinsi, 2018.

Berdasarkan gambar 1 terlihat bahwa jumlah armada menurut izin pada 8 trayek studi sangat berfariasi. Jumlah armada menurut izin pada trayek Baruga-Bambaea dan trayek Baruga-Boepinang adalah 13 kendaraan, jauh lebih sedikit dibandingkan jumlah armada menurut izin pada trayek lainnya. Sedangkan jumlah armada terbanyak terdapat pada trayek Baruga-Torobulu, Baruga-Lainea dan trayek Baruga-Palangga yakni sebanyak 17 kendaraan.

\section{Evaluasi Tarif Kendaraan}


Dari hasil survei yang dilakukan pada armada trayek di Terminal Baruga, diperoleh tarif kendaraan saat ini dari masing-masing trayek Angkutan Kota Dalam Provinsi. Adapun jumlah tarif kendaraan masing-masing trayek dapat dilihat pada gambar 2.

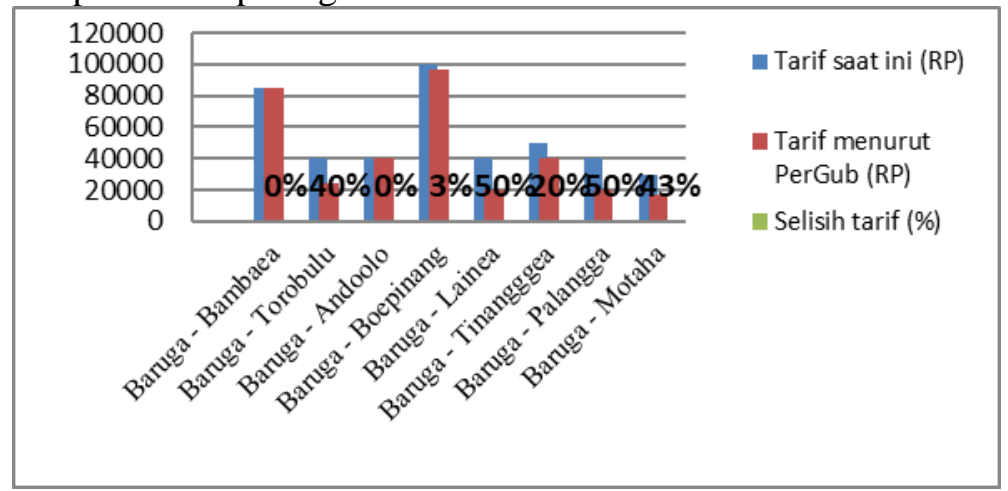

Gambar 2 : Grafik Evaluasi Tarif Kendaraan

Sumber : Standar Peraturan Gubernur dan Data Primer, 2018.

Dari gambar 2 menunjukkan bahwa evaluasi tarif kendaraan yang beroperasi saat ini dengan tarif kendaraan menurut Peraturan Gubernur, hanya dua trayek kendaraan yang tarif kendaraannya sesuai dengan tarif kendaraan menurut Peraturan Gubernur, trayek tersebut ialah trayek jurusan Baruga Bambaea dan Baruga - Andoolo. Sedangkan enam trayek lainnya tidak sesuai dengan Peraturan Gubernur yang ada. Berdasarkan hasil penelitian pada armada trayek yang beroperasi di terminal Baruga, mereka mengatakan bahwa penyebab tingginya tarif kendaraan pada trayek mereka disebabkan karena harga bahan bakar minyak yang semakin tinggi.

\section{Waktu Perjalanan Pulang Pergi}

Dari survei statis di titik pengamatan dapat ditentukan waktu perjalanan tiap trayek. Analisis waktu perjalanan tiap trayek dapat dilihat dari data selisih waktu antara kedatangan yang berurutan untuk kendaraan yang sama.

Adapun analisis perjalanan pergi pulang dapat dilihat pada gambar 3 .

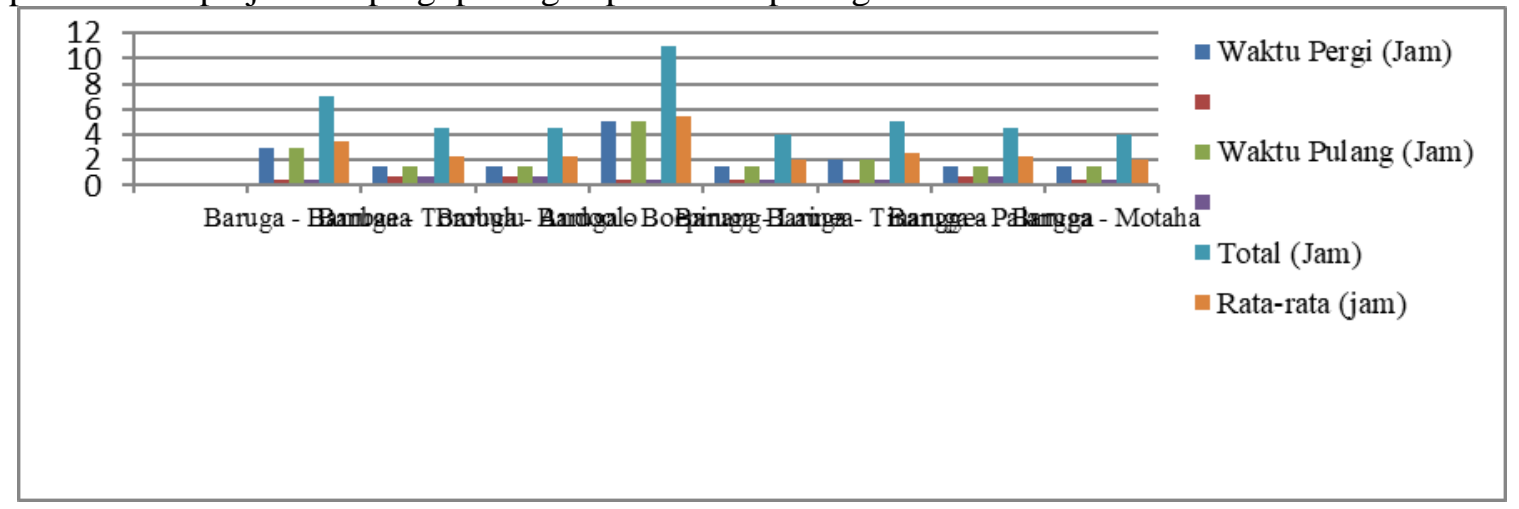

Gambar 3 : Grafik Waktu Perjalanan Pergi Pulang

Sumber : Hasil Analisis, 2018.

Dari gambar 3 menunjukkan bahwa rata-rata waktu perjalanan pergi pulang dari 8 trayek di Terminal Baruga sangat berfluktuasi dari 2.00 sampai 5,5 jam/kendaraan tiap trayeknya. Berdasarkan hasil perhitungan rata-rata waktu perjalanan pergi pulang di terminal Baruga hanya 6 trayek yang memenuhi standar Bank Dunia, trayek tersebut ialah trayek Torobulu, Andoolo, Lainea, Tinanggea, Palangga dan Motaha. Sedangkan 2 trayek lainnya yaitu trayek Baruga-Bambaea dan trayek Baruga-Boepinang tidak memenuhi standar World Bank. Hal ini dipengaruhi oleh panjang rute dari trayek Baruga-Bambaea dan 
trayek Baruga-Boepinang yang amat jauh. Adapun waktu perjalanan pergi pulang menurut World Bank : rata-rata 1-1,5 jam, maksimum 2-3 jam.

\section{Frekuensi Kendaraan}

Dengan menggunakan data "nama trayek" dari survei untuk ke 8 trayek di titik pengamatan, maka dapat dihitung frekuensi kendaraan untuk setiap trayek kendaraan di terminal. Hasil rekapitulasi data frekuensi kendaraan dapat dilihat pada grafik berikut ini.

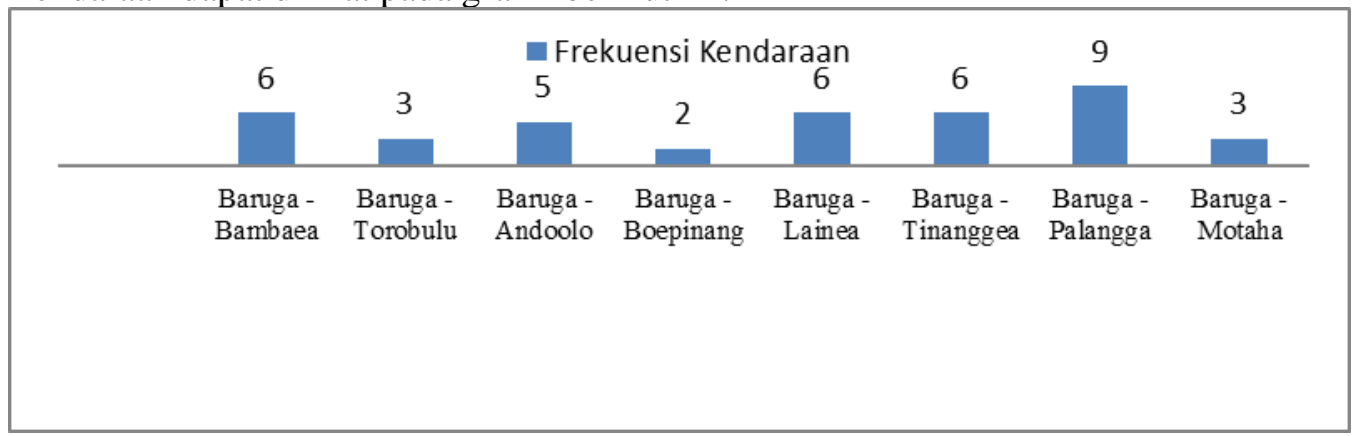

Gambar 4 : Grafik Frekuensi Kendaraan

Sumber : Data Primer, 2018.

Dari gambar 4 menunjukkan bahwa frekuensi kendaraan dari 8 trayek di terminal Baruga sangat berfluktuasi dari 2 kendaraan sampai 9 kendaraan. Frekuensi kendaraan terbanyak terdapat pada trayek Palangga yaitu 9 kendaraan. Berdasarkan standar frekuensi kendaraan rekomendasi World Bank jumlah frekuensi kendaraan pada jam sibuk dianjurkan 12 kendaraan, dan pada jam tidak sibuk frekuensi kendaraan dianjurkan 6 kendaraan. Sehingga Trayek yang memenuhi standar World Bank yaitu trayek Bambaea, Lainea, Tinanggea dan Palangga. Sedangkan trayek yang tidak memenuhi standar yaitu trayek Torobulu, Andoolo, Boepinang dan Motaha. Rendahnya frekuensi kendaraan yang ada di terminal Baruga disebabkan oleh banyaknya kendaraan angkutan kota dalam provinsi yang parkir di luar terminal. Banyak kendaraan yang masih beroperasi di pasar rakyat baruga hal ini mengakibatkan rendahnya frekuensi kendaraan yang ada di terminal Baruga saat ini.

\section{Faktor Muat (Load Faktor)}

Data faktor muat untuk setiap trayek diambil dengan merata-ratakan jumlah penumpang naik dan membandingkan dengan kapasitas kendaraan.

Misalnya faktor muat kendaraan pada trayek Baruga-Bambaea.

Load Faktor $=\frac{\text { jumlah penumpang }}{\text { kapasitas kendaraan }} \times 100$

Diketahui :

- Jumlah penumpang $=4$ orang

- Kapasitas kendaraan $=8$ orang

Maka load faktor trayek Baruga - Bambaea adalah :

Load Faktor $\quad=\frac{4}{8} \times 100 \%=50 \%$.

Dari perhitungan di atas diperoleh load faktor trayek Baruga - Bambaea sebesar 50\%. Untuk melihat load faktor dari 8 trayek studi dapat dilihat pada gambar 5 . 


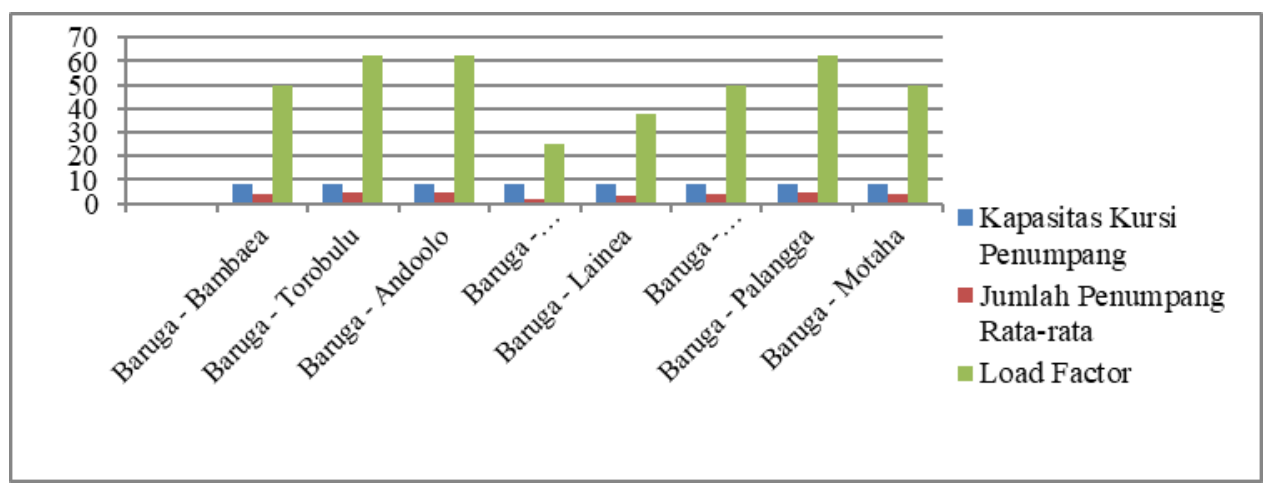

Gambar 5 : Grafik Faktor Muat

Sumber : Hasil Analisis Data, 2018.

Dari gambar 5 menunjukkan bahwa faktor muat kendaraan dari 8 trayek di terminal Baruga sangat berfluktuasi dari $25 \%$ sampai $62,5 \%$. Hasil perhitungan faktor muat dari 8 trayek di terminal Baruga di bawah $100 \%$. Faktor muat tertinggi terdapat pada trayek Torobulu, Andoolo dan trayek Palangga sebesar $62,5 \%$, sedangkan faktor muat terendah terdapat pada trayek Boepinang sebesar $25 \%$. Faktor muat untuk trayek Bambaea, Tinanggea, dan trayek Motaha sebesar 50\% dan untuk trayek Baruga-Lainea Faktor muat sebesar $37,5 \%$. Rendahnya faktor muat penumpang angkutan kota dalam provinsi di terminal Baruga disebabkan oleh banyaknya penumpang yang menunggu mobil penumpang umum di pasar rakyat Baruga. Selain itu adanya sistim telefon penumpang mengakibatkan para penumpang menunggu jemputan di kediaman masing-masing sehingga hal tersebut mengakibatkan rendahnya faktor muat penumpang yang ada di terminal Baruga.

\section{Selisih Waktu (Time Headway)}

Selisih waktu (time headway) kendaraan dapat diperoleh dengan menghitung selisih jam berangkat antara kendaraan. Misalnya selisih waktu untuk trayek Baruga - Bambaea.

Selisih waktu (headway) $=\frac{60}{\text { Q/jam }}$

untuk mengetahui selisih waktu maka Q/jam trayek Bambaea harus diketahui jam kerja kendaraan. Sehingga :

1 hari $=24$ jam.

1 hari kerja $=08.00-17.00=9$ jam kerja.

Maka Q/jam $=\frac{6}{9}=\frac{2}{3}$ kendaraan per jam.

Karena Q/jam telah diperoleh sehingga selisih waktu (time headway) dari trayek Bambaea ialah :

Selisih waktu $=\frac{60}{Q / j a m}=\frac{60}{\frac{a}{a}}=\frac{180}{2}=90$ menit.

Rekapitulasi waktu siklus dari 8 trayek dapat dilihat pada gambar 6 . 


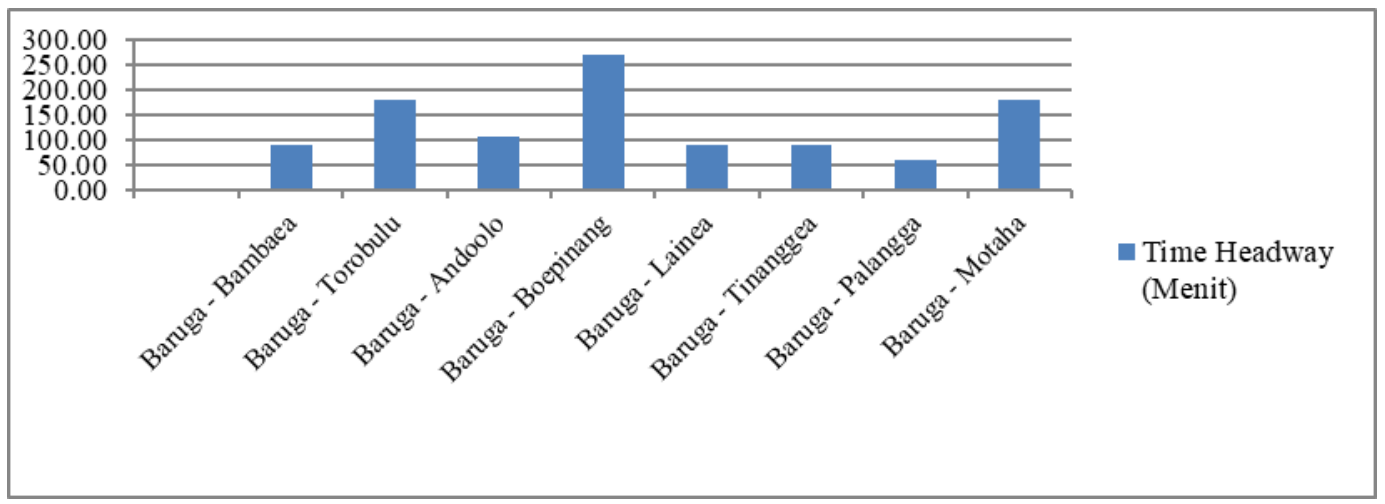

Gambar 6 : Grafik Selisih Waktu (time headway)

Sumber : Hasil Analisis Data, 2018.

Dari gambar 6 menunjukkan bahwa selisih waktu (time headway) dari 8 taryek di terminal Baruga sangat berfluktuasi dari 60 menit sampai 270 menit. Hasil perhitungan selisih waktu kendaraan pada 8 trayek studi di terminal Baruga diketahui selisih waktu terrendah terdapat pada trayek Baruga-Palangga yaitu 60 menit dan selisih waktu tertinggi terdapat pada trayek Baruga-Boepinang yaitu 270 menit. Selisih waktu pada trayek Bambaea, Lainea dan trayek Tinanggea yaitu 90 menit, pada trayek Torobulu dan Motaha selisih waktu kendaraan yaitu 180 menit dan pada trayek Baruga-Andoolo selisih waktu kendaraan 108 menit. Berdasarkan hasil perhitungan waktu siklus 8 trayek studi di terminal Baruga tidak satupun yang memenuhi standar dari World Bank. Lamanya selisih waktu angkutan kota dalam provinsi di terminal Baruga ini dipengaruhi oleh kurangnya penumpang yang ada di dalam terminal Baruga, sehingga mengakibatkan kendaraan penumpang angkutan kota dalam provinsi mengulur waktu tibanya di dalam terminal Baruga. Adapun menurut standar Bank Dunia selisih waktu (time headway) rata-rata untuk kinerja operasional kendaraan $1-12$ menit.

\section{Jumlah Trip Dan Jarak Tempuh Kendaraan/Hari}

Jumlah trip merupakan banyaknya kendaraan melakukan perjalanan pergi pulang tujuan. Satu kali trip dinyatakan dengan satu kali kendaraan melakukan pergi pulang perjalanan.

Sedangkan jarak tempuh merupakan panjak lintasan yang dilalui oleh kendaraan dari asal menuju ke tujuan.

Jumlah trip dan jarak tempuh dari 8 trayek studi di terminal Baruga dapat dilihat pada gambar 7:

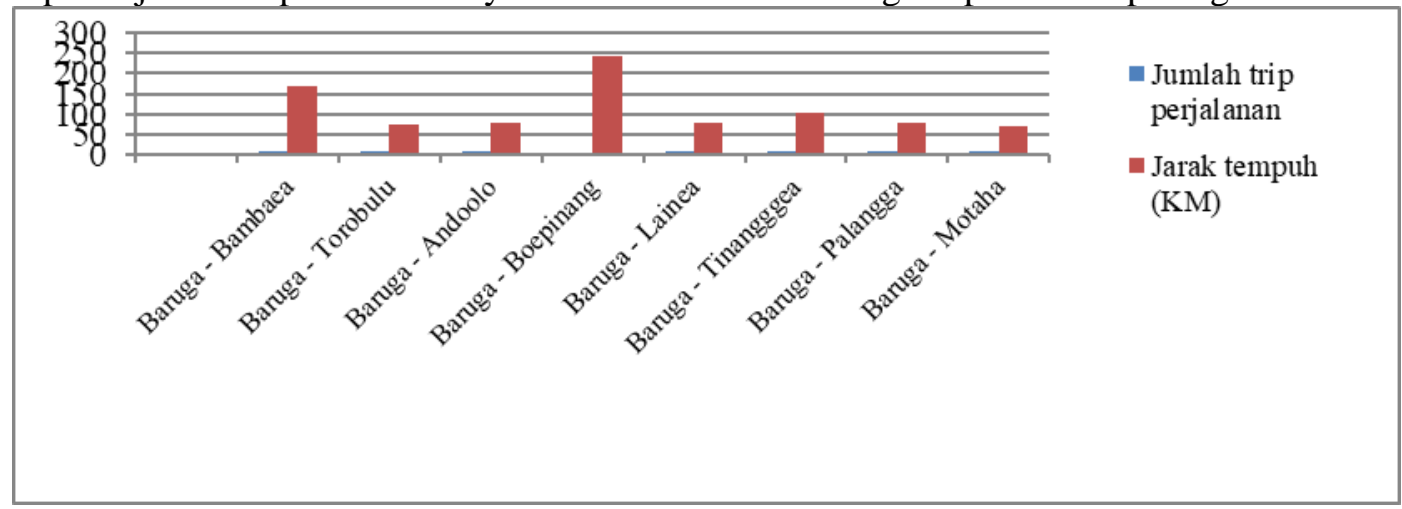

Gambar 7 : Grafik Jumlah Trip dan Jarak Tempuh Kendaraan Per Hari

Sumber : Data Primer 2018. 
Dari gambar 7 menunjukkan bahwa jumlah trip dan jarak tempuh kendaraan per hari dari 8 trayek studi di terminal Baruga sangat berfluktuasi dari 2 sampai 9 jumlah trip perjalanan dan $70 \mathrm{~km}$ sampai 245 $\mathrm{km}$ jarak tenpuh kendaraan per hari. Perbedaan Jumlah trip perjalanan angkutan kota dalam provinsi di terminal Baruga dipengaruhi oleh jumlah penumpang dan jarak tempuh dari masing-masing trayek yang beroperasi. Akan tetapi tidak semua armada trayek angkutan dengan jarak tempuh terendah melakukan 2 kali trip perjalanan. Hal ini dipengaruhi oleh faktor fisik. Trayek yang melakukan 2 kali trip perjalanan adalah trayek Torobulu, Andoolo, Lainea, Tinanggea dan trayek Motaha.

\section{Waktu Siklus}

Waktu siklus adalah waktu yang dibutuhkan kendaraan untuk melayani perjalanan penumpang dari asal menuju ke tujuan lalu kembali lagi ke asal. Sebagai contoh trayek Baruga-Bambaea, dengan menjumlahkan waktu tempuh dari Baruga ke Bambaea dan waktu tempuh dari Bambaea ke Baruga dengan deviasi perjalanan kedua waktu tempuh tersebut, serta menjumlahkan dengan waktu istirahat (lama tinggal) kendaraan di Baruga dan Bambaea.

Contoh perhitungan :

Untuk memperoleh waktu siklus, deviasi waktu perjalanan harus dicari terlebih dahulu. Berdasarkan persamaan (2.10), deviasi perjalanan adalah 5\% dari waktu perjalanan dari asal ke tujuan suatu kendaraan, sehingga deviasi perjalanan trayek Baruga-Bambaea adalah :

$\sigma=T A B \times 5 \%$

$\sigma=210 \times \frac{5}{100}=10,5$ menit.

Karena deviasi perjalanan telah diketahui, maka waktu siklus dapat diketahui dengan cara:

1) Terminal Baruga

Waktu perjalanan dari Baruga ke Bambaea $=3,5$ jam $=210$ menit.

Deviasi waktu perjalanan $\quad=10,5$ menit.

Waktu henti kendaraan di Baruga $\quad=0,5$ jam $=30$ menit.

2) Bambaea

Waktu perjalanan dari Bambaea ke Baruga $=3,5$ jam $=210$ menit.

Deviasi waktu perjalanan

$=10,5$ menit.

Waktu henti kendaraan di Bambaea

$=0,5 \mathrm{jam}=30$ menit.

Waktu siklus dari Terminal Baruga ke Bambaea:

$=(210+210)+(10,5+10,5)+(30+30)=501$ menit $=8,35 \mathrm{jam}$

Rekapitulasi waktu siklus untuk 8 trayek studi dapat dilihat pada gambar 8:

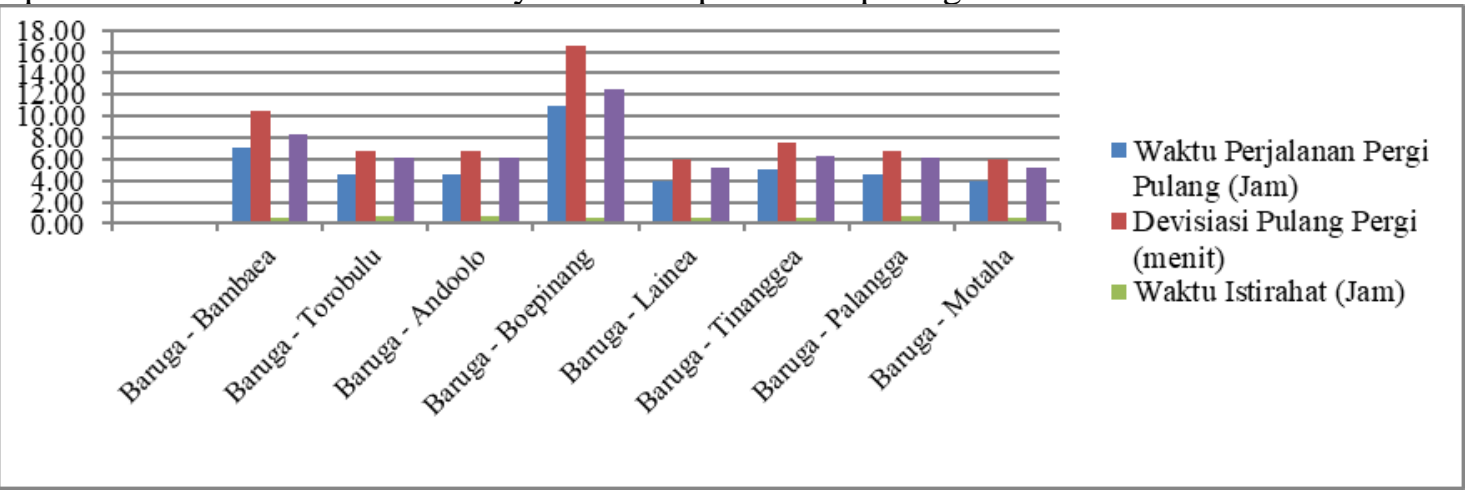

Gambar 8: Grafik Waktu Siklus

Sumber : Hasil Analsis Data, 2018. 
B.

Provinsi Di Terminal Baruga
1. . Kapasitas kendaraan
Kebutuhan Moda Angkutan Antar Kota Dalam

\begin{tabular}{|c|c|c|c|c|}
\hline \multirow{3}{*}{ 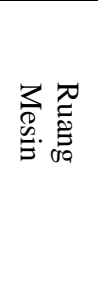 } & sopir & Seat B & Seat $C$ & \multirow{2}{*}{ 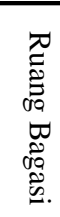 } \\
\hline & & Seat B & Seat $C$ & \\
\hline & Seat $A$ & & & \\
\hline
\end{tabular}

Gambar 1 : Sketsa MPU.

Pada terminal Baruga jenis kendaraan AKDP yang digunakan untuk ke 8 trayek ialah mobil pribadi jenis Avanza. Sehingga berdasarkan gambar di atas dapat diketahui kapasitas tempat duduk sesuai dengan kondisi di lapangan yaitu :

1) Pada bangku depan (seat A), jumlah penumpang yang dapat ditampung adalah 1 penumpang.

2) Pada bangku tengah (seat B), jumlah penumpang yang dapat ditamping adalah 4 penumpang.

3) Pada bangku belakang (seat $\mathrm{C}$ ), jumlah penumpang yang dapat ditampung adalah 3 penumpang.

Sehingga total keseluruhan penumpang yang dapat diangkut oleh kendaraan ini adalah:

$\mathrm{Cv}=1+4+3=8$ penumpang.

\section{Jumlah Penumpang}

Jumlah penumpang per kendaraan per hari pada setiap trayeknya diperoleh dari rata-rata jumlah penumpang pada tiap trayeknya kemudian dikalikan dengan jumlah armada yang beroperasi pada tiap trayeknya.

Misalnya perhitungan jumlah penumpang pada trayek Baruga - Bambaea :

1) Jumlah penumpang rata - rata $=4$ orang.

2) Jumlah armada yang beroperasi $=6$ orang.

Sehingga total jumlah penumpang pada trayek Baruga - Bambaea adalah :

4 × $6=24$ orang.

Hasil perhitungan jumlah penumpang per kendaraan dapat dilihat pada gambar 2.

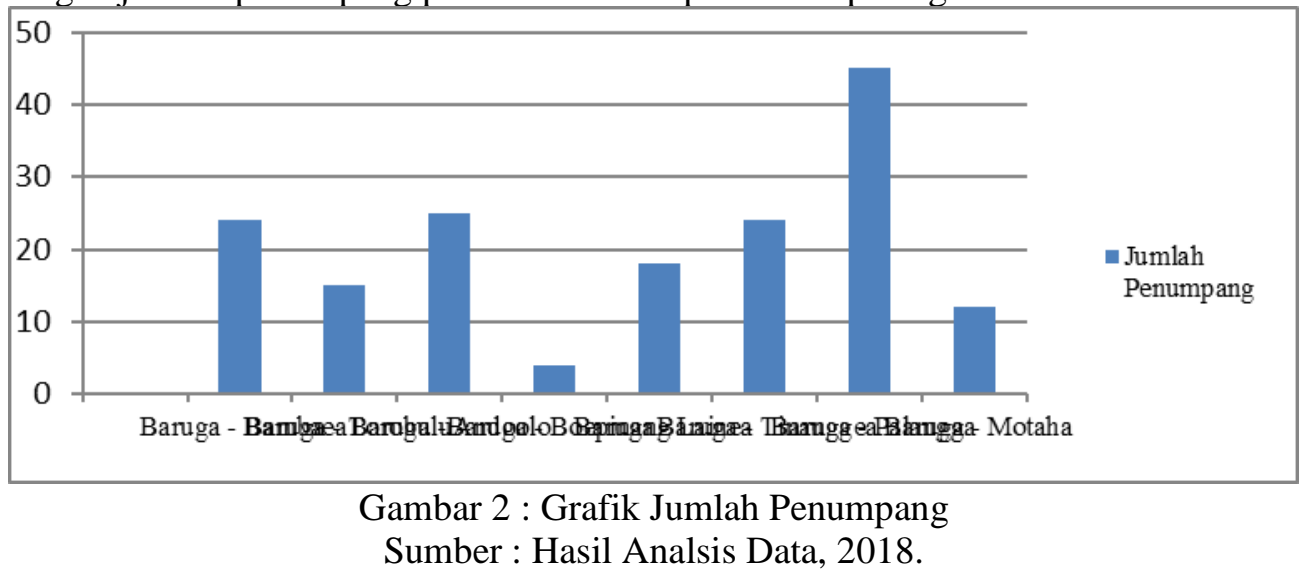

Dari gambar 2 menunjukkan bahwa jumlah penumpang per kendaraan pada 8 trayek studi di terminal Baruga sangat berfluktuasi dari 4 penumpang sampai 45 penumpang. Hasil perhitungan jumlah penumpang, diketahui pada trayek Baruga-Palangga merupakan trayek dengan jumlah penumpang paling tinggi yaitu 45 penumpang per kendaraan per hari. Sedangkan jumlah penumpang terendah terdapat pada trayek Baruga-Boepinang yaitu sebesar 4 penumpang per kendaraan per hari. Dari hasil perhitungan 
jumlah penumpang 8 trayek studi di terminal Baruga tidak ada satupun trayek yang memenuhi standar Pedoman Teknis Penyelenggaraan Angkutan Penumpang Umum di Wilayah Perkotaan Dalam Trayek Tetap dan Teratur yakni 250 - 300 penumpang/kendaraan/hari. Hal ini disebabkan karena tidak semua kendaraan angkutan kota dalam provinsi beroperasi di dalam terminal Baruga. Ada beberapa kendaraan yang beroperasi di pasar rakyat Baruga hal ini menyebabkan penumpang memilih angkutan yang letaknya lebih dekat dari tempat tinggalnya. Selain itu ada beberapa armada angkutan AKDP yang memakai sistim via telefon penumpang, hal ini memudahkan para penumpang untuk mendapatkan mobil angkutan menuju tempat tujuan mereka. Para penumpang cukup menelfon armada angkutan untuk menjemputnya tanpa repot-repot menunggunya di terminal. Hal inilah yang menyebabkan kurangnya jumlah penumpang yang ada di terminal Baruga saat ini.

\section{Jumlah Kendaraan Yang Diperlukan}

Sesuai dengan data trayek dapat dihitung jumlah kendaraan yang beroperasi sepanjang hari survei. Dari hasil analisis jumlah kendaraan yang beroperasi dapat dilihat bahwa tidak ada trayek yang memiliki faktor ketersediaan pada saat survei $100 \%$. Adapun jumlah kendaraan yang dibutuhkan juga dapat dihitung dari waktu siklus dibagi dengan selisih waktu (time headway) kemudian ditambah 10 sebagai kendaraan cadangan.

Misalnya perhitungan faktor ketersediaan kendaraan untuk trayek Baruga - Bambaea:

- Jumlah kendaraan yang beroperasi $=6$

- Jumlah kendaraan menurut izin $=13$

Sehingga faktor ketersediaan kendaraan untuk trayek Baruga - Bambaea adalah $: \frac{6}{13} \times 100 \%=46 \%$

Contoh perhitungan jumlah kendaraan yang dibutuhkan untuk trayek Baruga -Bambaea :

- Waktu siklus trayek Baruga - Bambaea=8.35 jam

- Selisih waktu trayek Baruga - Bambaea $=90=1.5$ jam

Sehingga jumlah kendaraan yang diperlukan untuk trayek Baruga - Bambaea adalah $: \frac{1.5}{8.35}+10=11$ kendaraan.

Jumlah kendaraan yang beroperasi dan jumlah kendaraan yang diperlukan dapat dilihat pada gambar 3 dan gambar 4.

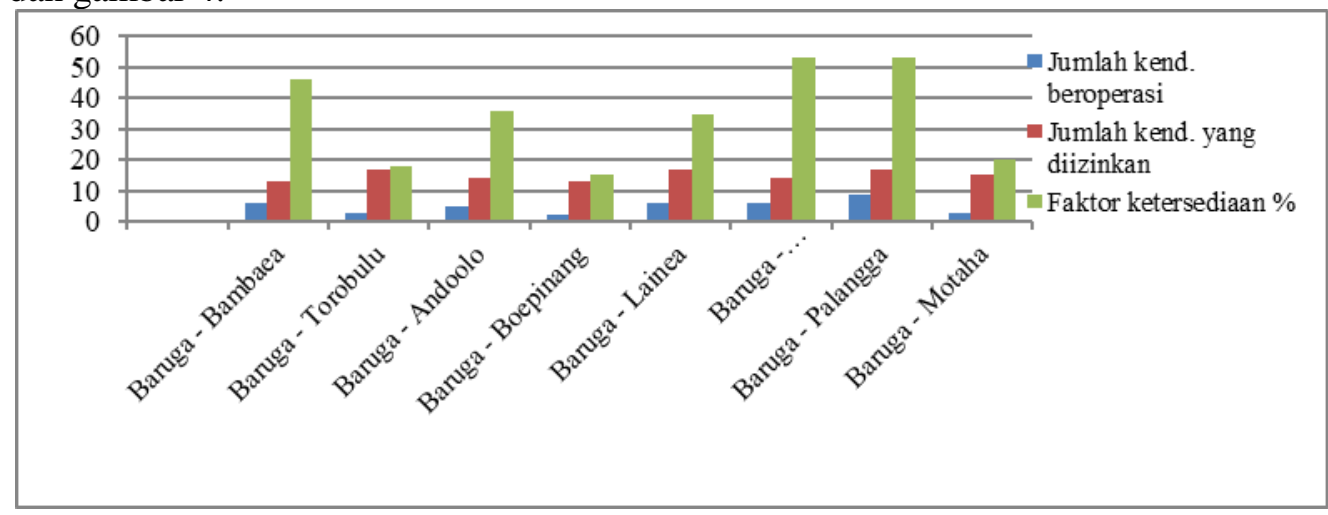

Gambar 3 : Grafik Jumlah Kendaraan Yang Beroperasi

Sumber : Data Primer, 2018.

Dari gambar 3 menunjukkan bahwa jumlah kendaraan yang beroperasi sangat berfluktuasi dari 2 kendaraan sampai 9 kendaraan per hari. Jumlah kendaraan yang beroperasi tertinggi terdapat pada trayek Baruga-Palangga yaitu 9 kendaraan sedangkan jumlah kendaraan terendah terdapat pada trayek BarugaBoepinang yaitu 2 kendaraan. Kendaraan yang beroperasi di terminal Baruga saat ini jauh lebih sedikit dibandingkan jumlah kendaraan yang diizinkan oleh Dinas Perhubungan Provinsi Sulawesi Tenggara. 
Rendahnya jumlah kendaraan yang beroperasi disebabkan karena tidak semua kendaraan beroperasi di dalam terminal Baruga, ada beberapa kendaraan yang masih beroperasi di pasar rakyat baruga. Sebelum adanya terminal baruga saat ini, pasar rakyat baruga merupakan terminal bagi angkutan kota dalam provinsi. Hal ini mengakibatkan kurangnya kendaraan AKDP yang beroperasi di dalam terminal.

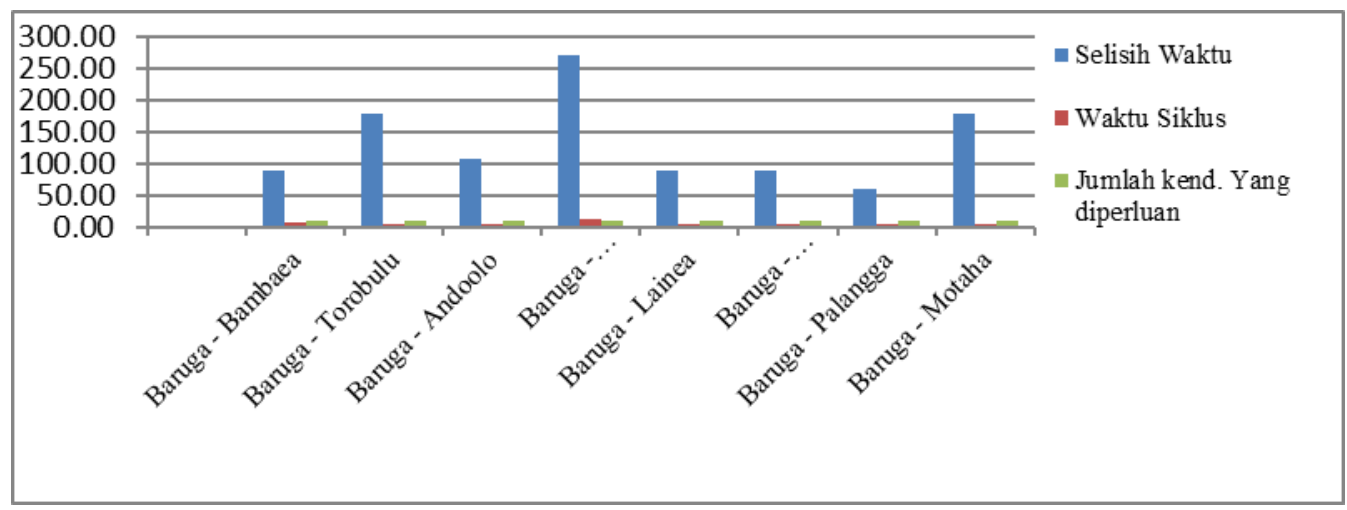

Gambar 4 : Grafik Jumlah Kendaraan Yang Diperlukan

Sumber : Hasil Analisis Data, 2018.

Dari gambar 4 terlihat bahwa jumlah kendaraan yang diperlukan pada 8 trayekangkutan kota dalam provinsi yang beroperasi saat ini di terminal Baruga. Untuk trayek Bambaea dan Motaha jumlah kendaraan yang diperlukan sebesar 11 kendaraan, sedangkan untuk trayek Torobulu, Andoolo, Boepinang, Lainea, Tinanggea dan Palangga jumlah kendaraan yang diperlukan sebesar 10 kendaraan. Kurangnya kendaraan angkutan yang beroperasi mengakibatkan kurangnya pula jumlah penumpang yang ada di terminal Baruga selain itu kurangnya kendaraan angkutan yang beroperasi mempengaruhi selisih waktu (time headway) dari masing-masing kendaraan. Dengan adanya penambahan kendaraan angkutan yang beroperasi di terminal Baruga diharapkan mampu menjadi daya tarik bagi para pengguna jasa angkutan kota dalam provinsi di terminal Baruga.

\section{4) Penyimpangan Trayek}

Penyimpangan trayek adalah perubahan jalur angkutan umum yang disebabkan oleh beberapa hal, misalnya sepinya penumpang sehingga banyak armada yang beroperasi tidak sesuai dengan rute yang berlaku. Pada ke 8 trayek yang ada di terminal Baruga, tidak ada satupun penyimpangan yang terjadi, karena hanya itu jalur akses yang menghubungkan masing-masing trayek ke tujuan penumpang.

\section{SIMPULAN}

1. Kinerja pelayanan Angkutan Kota Dalam Provinsi di Terminal Baruga Kota Kendari hanya sebagian kecil yang memenuhi standar World Bank. Perjalanan pergi pulang dari 8 taryek studi hanya 6 trayek yang memenuhi standar World Bank, yaitu trayek Torobulu, Andoolo, Lainea, Tinanggea, Palangga dan Motaha. Untuk frekuensi kendaraan hanya 4 trayek yang memenuhi standar World Bank yaitu trayek Bambaea, Lainea, Tinanggea dan Palangga. Dari aspek faktor muat yang tertinggi terdapat pada trayek Torobulu, Lainea dan Palangga, sedangkan yang terendah terdapat pada trayek Boepinang. Dari aspek selisih waktu 8 trayek studi tidak satupun yang memenuhi nilai standar World Bank.Dari aspek waktu siklus 8 trayek studi hanya 1 trayek yang tidak memenuhi standar, yaitu trayek Baruga - Boepinang.

2. Kebutuhan moda Angkutan Kota Dalam Provinsi di Terminal Baruga belum memenuhi standar karena Jumlah kendaraan yang beroperasijauh lebih sedikit dari jumlah kendaraan yang ditetapkan oleh Dinas Perhubungan Provinsi Sulawesi Tenggara. 


\section{DAFTAR PUSTAKA}

Direktorat Bina Sistem Transportasi Perkotaan. (2009). Perencanaan Teknis Sistem Pengelolaan Transportasi Untuk Kota Sedang Dan Kota Kecil. Jakarta : Kementerian Perhubungan Republik Indonesia.

Keputusan Menteri Perhubungan Nomor 35 Tahun 2003 Tentang Penyelenggaraan Angkutan Orang di Jalan Dengan Kendaraan Umum Pasal 1.

Keputusan Direktur Jendral Perhubungan Darat Nomor: SK.687/AJ.206/DRJD/2002.

Pedoman Teknis Penyelenggaraan Angkutan Penumpang Umum Di Wilayah Perkotaan Dalam Trayek Tetap dan Teratur. Jakarta: Departemen Perhubungan RI.

Risdiyanto., Efendi. Y., Kresnanto. N. C.2013. “Kajian Teknis Kinerja Angkutan Antar Kota Dalam Provinsi Daerah Istimewa Yogyakarta”. Jurnal Teknik Volume 3, Nomor 2, ISSN 2088-3676.

Sabiq., Wildanus, 2015. "Evaluasi Kinerja Trayek Utama Angkutan Umum Perkotaan Jember". Skripsi, Jurusan Teknik Sipil, Fakultas Teknik, Universitas Jember, Jember.

Sibagariang. H., Pandia, I.J 2013. "Kinerja dan Teknis Pelayanan Terminal Angkutan Umum Kota Sibolga". Universitas Sumatera Utara, Medan.

Yohanes, T. Safe., Udiana. I.M., Bella, R. A. 2015. "Evaluasi Kinerja Angkutan Umum Trayek Terminal Oebobo-Terminal Kupang PP dan Terminal Kupang-Noelbaki PP”.

World Bank. 1987. Bus Service: Reducing Cost and Raising Standarts. Washington,D.C: W orld Bank Technical Paper No. 68. 